\title{
Weakness of the Embodied Energy Assessment on Construction: A Literature Review
}

\author{
Kailun Feng ${ }^{1}$; Yaowu Wang ${ }^{2}$; Weizhuo $\mathrm{Lu}^{3}$; and Xiaodong $\mathrm{Li}^{4}$ \\ ${ }^{1}$ Ph.D. Candidate, School of Management, Harbin Institute of Technology, Harbin, China, \\ 150001.E-mail: fklws2013@163.com \\ ${ }^{2}$ Professor, Dept. of Construction Management, Harbin Institute of Technology, Harbin, China, \\ 150001. E-mail: ywwanghit@vip.163.com \\ ${ }^{3}$ Senior Lecturer, Dept. of Civil, Environmental and Natural Resources Engineering, Luleå Univ. \\ of Technology, Luleå, Sweden, 97187. E-mail: weizhuo.lu@1tu.se \\ ${ }^{4}$ Professor, Dept. of Construction Management, Harbin Institute of Technology, Harbin, China, \\ 150001. E-mail: lixdhit@ vip.163.com
}

\begin{abstract}
Construction industry consumes a large amount of energy and resources in both developed and developing countries. The opportunities for improving energy efficiency of construction could be research considering energy assessment and thereby providing suggestions for practical action. The research on embodied energy (EE) is an important endeavor of this orientation. The aim of this review paper is to investigate and analyze research weakness of present embodied energy study on construction. To do so, a professional searching tool called Academic 2.0 was employed to collect relevant publications from multiple databases in this research field. After obtaining relevant studies, paper elimination and information collection are performed based on predefined criteria. Data analysis was then performed and showed that assessment method, data sources, and research boundary differed dramatically amongst present study. And, they are weaknesses of current study. These results could help researchers deeply understand present study weakness and then overcome it in further study.
\end{abstract}

\section{INTRODUCTION}

The construction industry has been regarded as one of the largest consumers of renewable and non-renewable natural resource, in particular the energy resource in the form of electricity or burning fossil fuels (Spence and Mulligan 1995). It has already been widely recognized that construction sector accounts for considerable contribution to energy consumption in the form of embodied energy and operation energy during construction and operation phase. Figure 1 shows some proportion results of energy consumption found by recent study or official data merely by construction industry (Ardente et al. 2008; Asif et al. 2007; Cui 2005; EIA 2010; Energy 2012; Jiang and Yang 2006; Levin et al. 1995; NISTIR 2007). It shows that at least 20 percent of total energy is consumed by construction, while construction contributes more than 40 percent in the research conducted by Levin et al. (1995).

Embodied energy and operation energy are two types of energy consumption in construction industry. And operation energy obtained more attention by researchers because it inherently occupies larger share in the whole life cycle of building (Gustavsson et al. 2010). However, as high efficiency building and equipment design employed widely, embodied energy which occur upstream before operation phase will becomes a more significant part (Dixit et al. 2010; Fieldson and Rai 2009). Therefore, embodied energy has been utilized as an important indictor to represent energy performance of building. Embodied energy is consisted of initial embodied energy, recurring energy and demolition energy (Yohanis and Norton 2002). And there are 
controversies on boundary of initial embodied energy. Dixit et al. (2010) maintained it begins at raw material and end at offsite transportation, while Yohanis and Norton (2002) stated it ends at construction accomplishment (shown in Figure 2). However, Dixit et al. (2010) proposed embodied energy begins at raw materials extraction and ends at building demolition. The concept of embodied energy is comprehensive and prolonged, and thus various researchers could study different aspects.

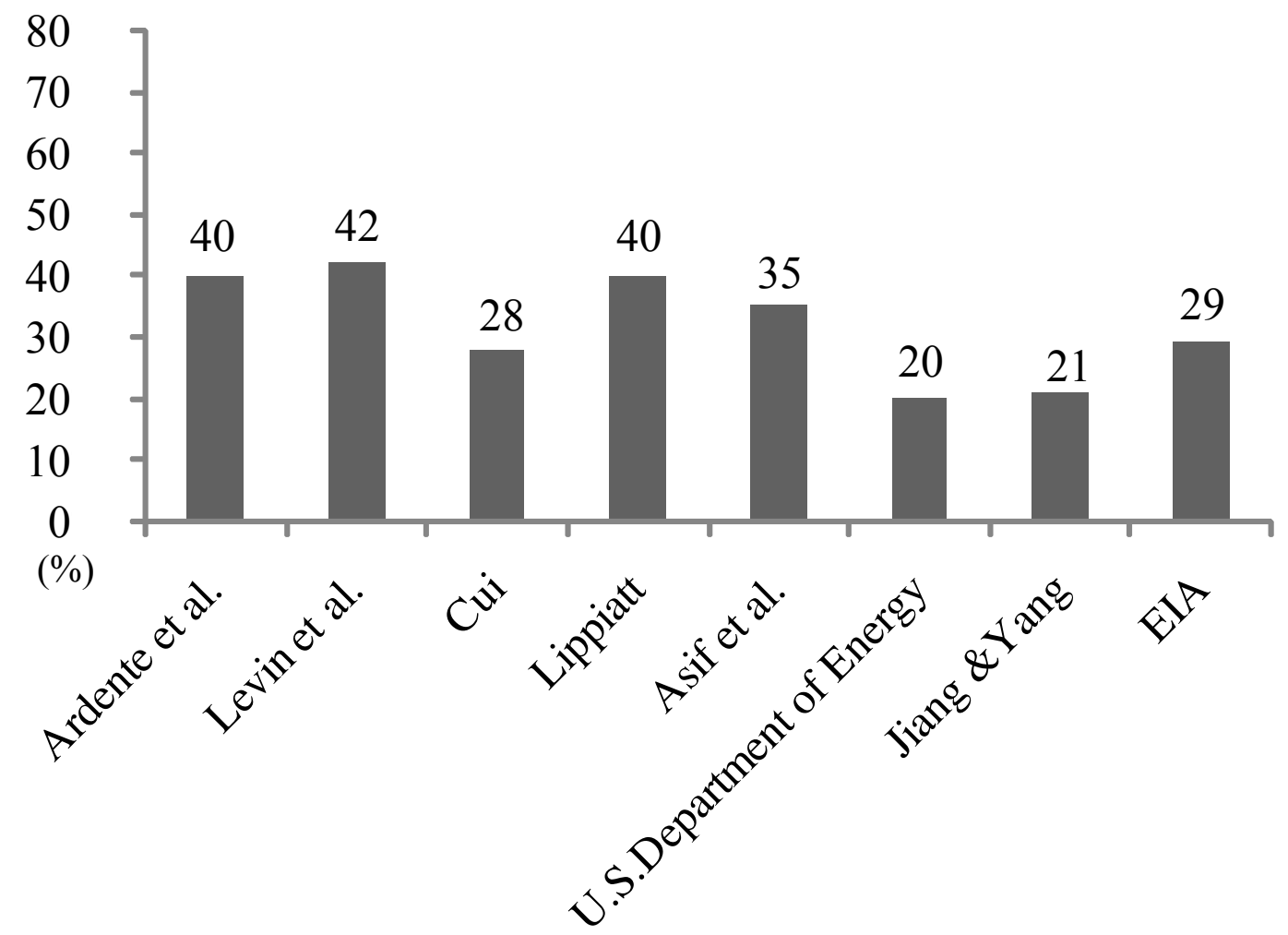

Figure 1. The energy consumption of construction from different studies.

Present research efforts: Study on the embodied energy derived from construction material is the most important and popular research orientation. Dixit et al. (2010) even maintained that reduction of embodied energy can only be achieved by low energy intensive materials selection. These studies concentrate on embodied energy in materials and provide suggestions for material selection. Numerous types of materials are used during construction through different manufacturing processes, in which energy are embodied in material through raw material extraction, processing, transportation and manufacturing (Ding 2004). According to Ramesh et al. (2013), energy embodied in construction materials account for 10 to 20 percent of the total energy used in the life cycle of building.

Another study orientation considers design scheme of building. Although materials selection is part of design work, this research orientation takes design as a relatively completed work rather than merely on material aspect. For instance, Miller et al. (2015) investigated embodied energy of different design pattern of concrete slab, and they found post-tensioned is the best design scheme which will reduce $23.7 \%, 39.83 \%$, and $49.1 \%$ in flat plate, flat slab, and beam \& slab floor system, respectively. Also, Monahan and Powell (2011) compared offsite panellised modular timber frame system with traditional systems, and they demonstrated that offsite panellised timber frame construction will decrease 30.5 percent of embodied energy. 


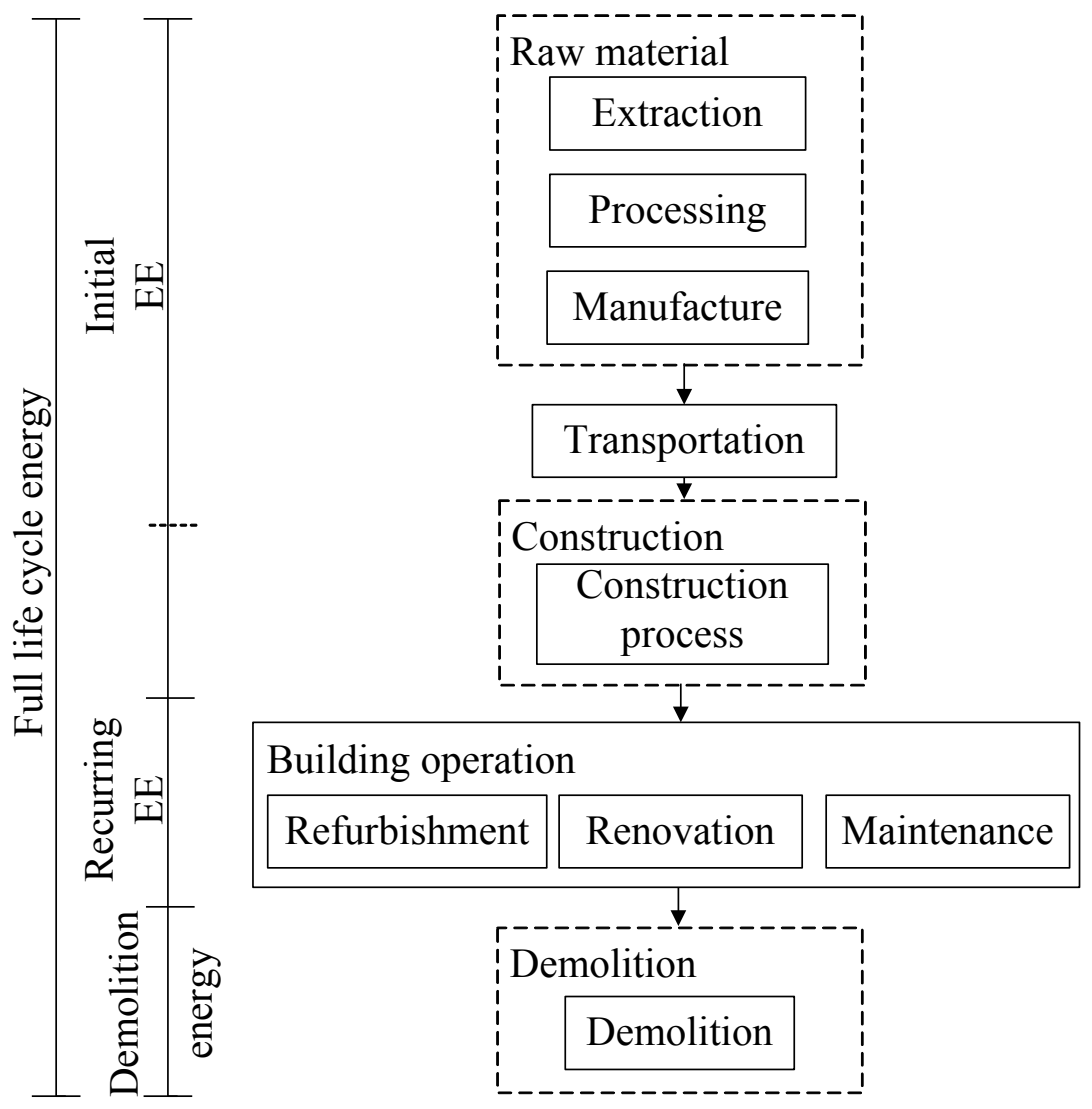

Figure 2. Full life cycle energy of building and boundary of embodied energy.

The activity within construction phase is regarded as an important aspect of embodied energy recently. Although construction phase indeed consumes less energy compared with operation, $\mathrm{Li}$ et al. (2010) proposed that it should be more intensive for the much shorter time lasting. Davies et al. (2014) stated in their study that preconstruction and construction activities can harm the life cycle energy, especially the initial embodied energy. Because construction process is naturally complex and constructors involve in construction actives directly, they concluded that it should established a framework to highlight the function of constructors to obtain prerequisite data for initial embodied energy assessment (Davies et al. 2014). The potential of reducing initial embodied energy during construction phase has also been emphasized in another research by Davies et al. (2015). Embodied energy derived from onsite activities including equipment using, assembly work and administration and energy is embodied as the form of material using, fossil fuel and electricity within these construction activities.

Present research weakness: As research in this field enriched, various hampers appear and block the further study. According to a broad literature view, different calculation method, inconsistent data source, and unclear research boundary are three frequently mentioned weaknesses in embodied energy research.

Dixit et al. (2010) reviewed extensive relevant literature to identify critical parameters influencing embodied energy measurement, in which different calculation method had been accused by ten embodied energy studies. The measured results measured by disparate calculation methods differ dramatically because of the inherent limitations of these methods (Dixit et al. 2010). Present study on embodied energy either follows the Life Cycle Assessment (LCA) standards or did not base any standard, but LCA can neither provide complete guidance nor 
address some important issues (Dixit et al. 2012). Abanda et al. (2013) also claimed that the quantification procedures of recent study is quite unclear.

Inconsistent data source is another weakness in embodied energy research. Four studies in Dixit et al. (2010) mentioned regarded inconsistent data as parameters will impact assessment results. Some researchers adopt embodied energy coefficient by their own study results, while others derive data from other professional database or other studies. However, Ding (2004), Junnila and Horvath (2003) cited from Dixit et al. (2010) proposed this different approaches influences the finally results significantly. Researchers have to adopt secondary data sources when they cannot obtain primary data. And Dixit et al. (2010) claimed secondary data sources are improper because of the inappropriate calculation method or different boundaries.

Meanwhile, the study relied on LCA also suffers from unavailable of primary data, which leads to uncertain and variable results (Dixit et al. 2010).

As analysis above, the concept of embodied energy is a comprehensive and prolonged. Miller proposed in 2001 that the interpretations of embodied energy is still an unclear and subjective (Dixit et al. 2010). Unclear research boundary derives from different interpretation of embodied energy for construction. The embodied energy study which takes some phases into account differs a lot on results with which considers other phases. This difference also makes the assessing results incomparable. Dixit et al. (2013) proposed system boundary is a key parameter causing variation, inaccuracy and incompleteness.

Although it is widely accepted the existence of these weaknesses, rare research has investigated and analyzed detail information of these weaknesses from present literatures as far as authors know. Which calculation method is often utilized, what kind of data sources is frequently used, and which phases are often included into system boundary are examples of this detail information. This detail information is still unclear, although many researchers have claimed that these weaknesses cause many hampers and blocks for further study.

The aim of this literature review is to investigate and analyze the detail information of weakness on embodied energy study for construction, which helps researchers in this field deeply understand and overcome current weakness. To do so, this study employed a professional searching tool called Academic 2.0 developed by ProQuest to search relevant literatures from multiple databases in this field. Paper elimination was performed with predefined criteria, and information collection and data analysis were then performed.

This study is the first try of analyzing the current limitation and problem in EE study on construction with information derived from paper review as far as authors know. Some claims are verified and some phenomena are found in this research.

\section{RESEARCH METHOD}

This research was carried out based on extensive literature review and then obtained relative data to be analyzed. Therefore the collection and selection method of publications are vital for final results. This section illustrates the collection and elimination criterion, and meanwhile, parameters of analysis were also carefully defined in this section.

Literature search: Relevant publications on embodied energy assessment for construction are searched with a specific searching tool name Academic 2.0 till January 2016. Academic 2.0 is a paper search engine integrating multiple databases developed by ProQuest. In this study, Academic 2.0 consists of the main peer-reviewed journals and conference proceedings in this field, including Web of Science, Engineering Village, Science Direct, EBSCO Host, and Scopus academic databases. An extensive and systemic searching can be achieved with this search 
engine. In order to obtain publications closely related to embodied energy for construction activities, authors conducted the searching with keywords 'embodied energy' AND/OR 'construction' in All Fields, showed only by peer-reviewed scholarly materials and screened them with journal article and conference proceedings. Searching results are also ranked with relevancy, then the top 60 relevant publications are selected as preliminary literatures. It should be noted that this study aims at investigate and analyze the major research weakness of EE on construction, rather than obtaining the complete relevant papers. Therefore reasonable numbers (60 in this study) of papers are enough for this investigation. Utilization of Academic 2.0 in this literature search insures the extension and diversity of researched publications.

Literature selection: However, parts of the publications searched still did not match the research topic but matched the research terms. Authors refined and filtered the preliminary literature with predefined criteria as follows:

(1) Study subjects are not or more than construction, these publications were searched because they matched "construction" term. For instance, the renewable electricity generation technology is the research topic of Rule et al. (2009), and construction is only a part of it.

(2) Research only focused on methods and technologies of EE assessment, these papers did not try to analyze EE performance of construction or provide suggestions for construction. For example, Wang and Shen (2014) attempted to improve existing EE estimate method using data quality indicators.

(3) Research objectives are construction sector, in which study is not a specific construction project, but the whole sector of a country. Such as Hong et al. (2016).

(4) Research objectives are agriculture or infrastructure. Although infrastructure is part of construction industry, there are many differences between infrastructure and building construction. Thus it was excluded so as to make assessment results comparable.

(5) In some papers EE were only mentioned, but not as research topic or turned into other environmental indictor, such as embodied carbon in Iddon and Firth (2013).

In total 30 papers were selected and others were eliminated with above criteria. These selected papers are shown in Table 1.

Table 1. Selected Publications in This Paper Review after Elimination.

\begin{tabular}{llll}
\hline Year & \multicolumn{1}{c}{ Reference } & Year & \multicolumn{1}{c}{ Reference } \\
\hline 2015 & Yokoyama et al. (2015) & 2014 & Kishore and Chouhan (2014) \\
2011 & Yeo and Gabbai (2011) & 2012 & Jiao et al. (2012) \\
2015 & Wen et al. (2015) & 2015 & Hashemi et al. (2015) \\
2009 & Shukla et al. (2009) & 2013 & Han et al. (2013) \\
2016 & Salcido et al. (2016) & 2010 & Goggins et al. (2010) \\
2014 & Reddy et al. (2014) & 2010 & Dixit et al. (2010) \\
2010 & Reddy and Kumar (2010) & 2015 & Dixit et al. (2015) \\
2003 & Reddy and Jagadish (2003) & 2015 & Davies et al. (2015) \\
2015 & Rauf and Crawford (2015) & 2014 & Davies et al. (2014) \\
2013 & Praseeda et al. (2013) & 2009 & Chel and Tiwari (2009) \\
2014 & Omar et al. (2014) & 2008 & Chau et al. (2008) \\
2011 & Noerwasito (2011) & 2012 & Chang et al. (2012) \\
2011 & Monahan and Powell (2011) & 2014 & Biswas (2014) \\
2015 & Miller et al. (2015) & 2014 & Bansal et al. (2014) \\
2013 & Kua (2013) & 2014 & Alwan and Jones (2014) \\
\hline
\end{tabular}


Parameters setting and analyzing: Process-based analysis, economic input/ output-based analysis, and hybrid analysis are three primary calculation methods used in construction EE research (Dixit et al. 2012). And Treloar (1998) categorized hybrid method into two types, process-based hybrid analysis and Input/output-based hybrid analysis. However, existing methods are all incomplete and inaccurate (Dixit et al. 2012). And this make assessing results of disparate assessing methods differ widely (Dixit et al. 2010). Therefore, this study set the calculation method as one of parameters to analyze the phenomenon that different methods are utilized in present study.

Crawford (2009) claimed that "unreliable and incomplete data" often hamper the decisionmaking process of building materials and assemblies. In the research of Dixit et al. (2010), ten parameters were identified as factors responsible for results variation and inconsistency, and three of them are related with data issues. After roughly reading within selected literature, author found that different data sources were employed into EE study. In order to figure out what kinds of data sources are often utilized and what hampers they will cause for study, data source was set as parameter to be analyzed, which defined as professional database (PD), local official database (LD), and individual research data (ID) in this research. Professional database is developed by professional organizations which focus on environmental service. They can be the international public organization such as Intergovernmental Panel on Climate Change (IPCC) established amongst international governments aiming at study the climate change problem caused by human activities, or research unit like Sustainable Energy Research Team (SERT) which set up inventory of carbon and energy (ICE) database (Hammond and Jones 2008). Davies et al. (2015) collected major professional databases from extensive literatures, including DEAM, GaBi, CFP, IBO, Synergia, ICE, DefraGuide. Local official database is the environmental or economic data demanded for EE assessment provided by government, for instance Guidelines to Defra's GHG Conversion Factors Annexes produced by U.K. government (Monahan and Powell 2011). Individual research data are secondary data assessed by separated research. Only one source (OID) and various data sources (VID) in a study are two different ways to make use of this secondary data, and it is also considered in this study.

Miller proposed that the definition of embodied energy is pretty subject by different authors. Dixit et al. (2010) maintained the unclear definition of embodied energy represent different opinions of research boundaries in embodied energy analyses. Hence, this study took the definition of each publication, to be specifically the system boundary as parameter to analyze the difference of each study.

As Dixit et al. (2010) concluded that results are considerable variations in different study in this field. Measurement results are thus taken as parameter to investigate whether exists distinctly differences within present research. This study also considered building type of assessed case project to figure out the connection between building type and calculated results.

\section{DATA ANALYSIS AND RESULTS DISCUSSION}

Data analysis: Analyzing the calculation method of selected papers, the proportions of different methods are presented in Figure 3. It can be seen in Figure 3, process-based analysis is still the most popular method utilized in EE study for construction, which accounts for 69 percent of all papers. Within hybrid analysis method, process-based hybrid and I/O-based hybrid are equal in number in publications. Meanwhile, 17 percent of selected research conducted EE assessment with Life cycle assessment (LCA) framework, which is not shown in Figure 3. This type of study is included into process-based method by authors because the basic procedure is 
unified with this method.

As defined above, PD, LD and ID stand for professional database, local official database and individual research data, respectively. And individual research data was divided into two parts, one research source and various sources using OID and VID to represent, respectively. As can be seen in Figure 4, ID accounts for the highest proportion (55 percent) of all types of database sources. And near half of ID is from various data sources. Some research utilize more than one type of data source in which authors integrated LD with ID, LD with PD, or ID with PD as study data source and they account for 20 percent of all publications. If takes the study which mixes database and VID as unsystematic database, it accounts for 43 percent of all selected publications.

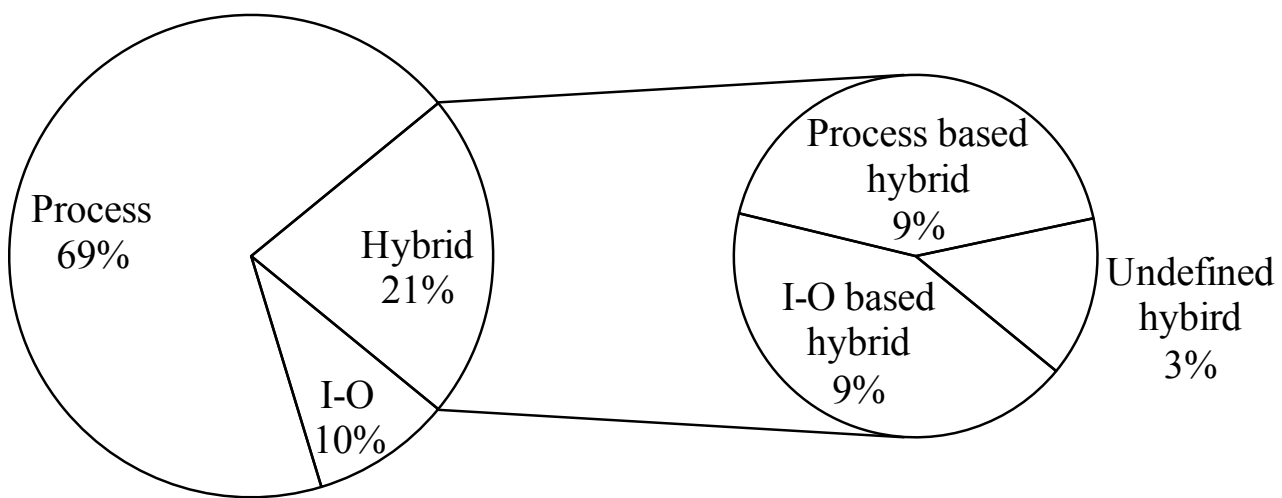

Figure 3. The proportion of calculation methods.

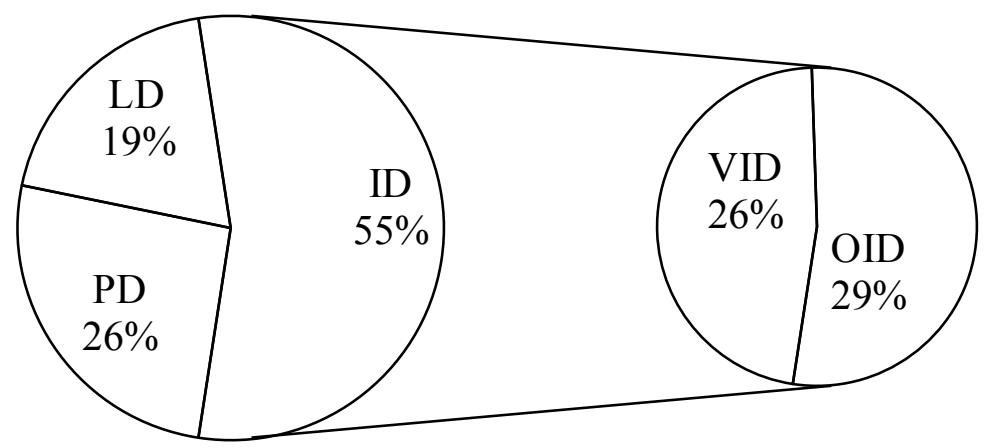

Figure 4. The proportion of adopted data source.

The study boundary of each selected publications is collected and the results are shown in Figure 5. The whole building phases which may related to embodied energy are defined as nine phases according to Yohanis and Norton (2002). And Figure 5 shows most of current researchers take material work (includes extraction, processing and manufacture), transportation and construction into research boundary. But some researchers, such as Dixit et al. (2010) held the opinion that the energy used for maintenance and refurbishment, besides energy for deconstruction should also be included in study boundary. As Figure 5 shows, the proportion of this study is still low (14\% for refurbishment, renovation and maintenance, $25 \%$ for demolition).

The calculated results of selected publications are shown in Figure 6 and Figure 7. Some research assessed different case projects and obtained several results, while some studies obtained embodied energy of specific material or structure, thus in total 21 assessing results of building are gained in this research. It should be noted that the results of Oka is cited from Dixit 
et al. (2010). It can be seen from Figure 6, majority of assessing results of residential are less than $5 \mathrm{GJ} / \mathrm{m}^{2}$, which account for $81 \%$ of all publications. The average value of embodied energy is $3.7 \mathrm{GJ} / \mathrm{m}^{2}$. The result of Rauf and Crawford is extremely higher than other results. As for commercial and public institutions building (shown in Figure 7), only one study result is less than $5 \mathrm{GJ} / \mathrm{m}^{2}$, and the average value is $14.2 \mathrm{GJ} / \mathrm{m}^{2}$. There is an extreme result $42.8 \mathrm{GJ} / \mathrm{m}^{2}$ obtained by Biswas (2014), which is far more than other results.

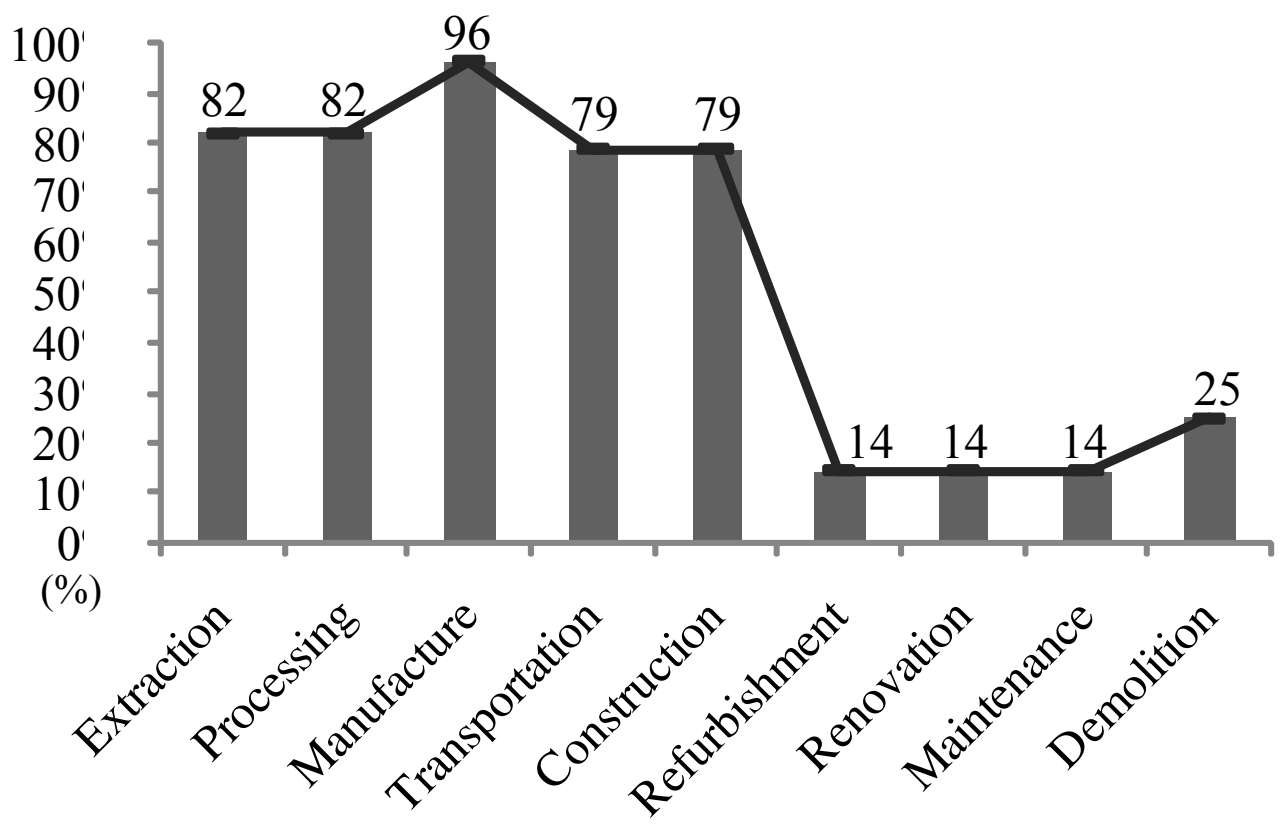

Figure 5. Distribution rate of study boundary.

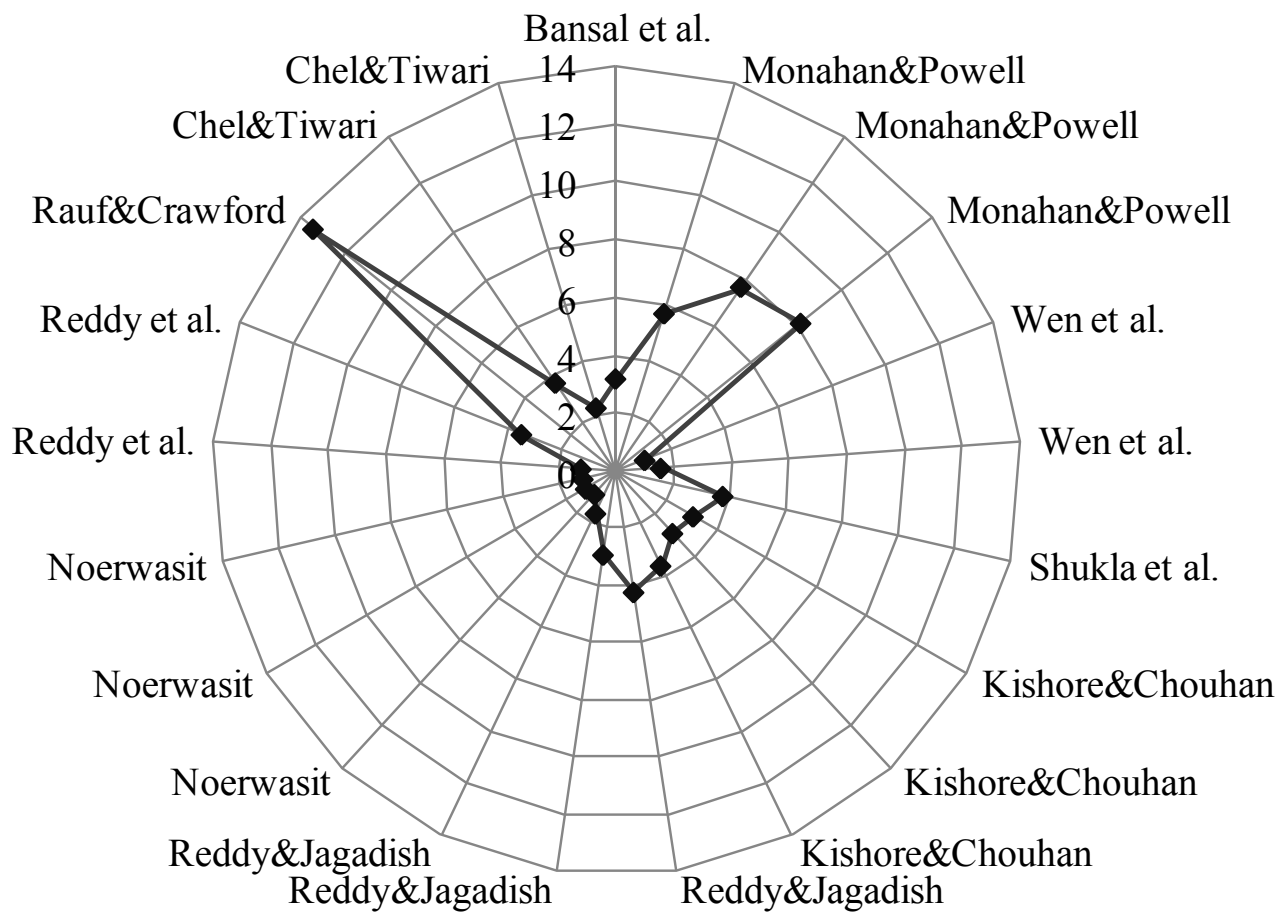

Figure 6. Results of embodied energy for residential building. 


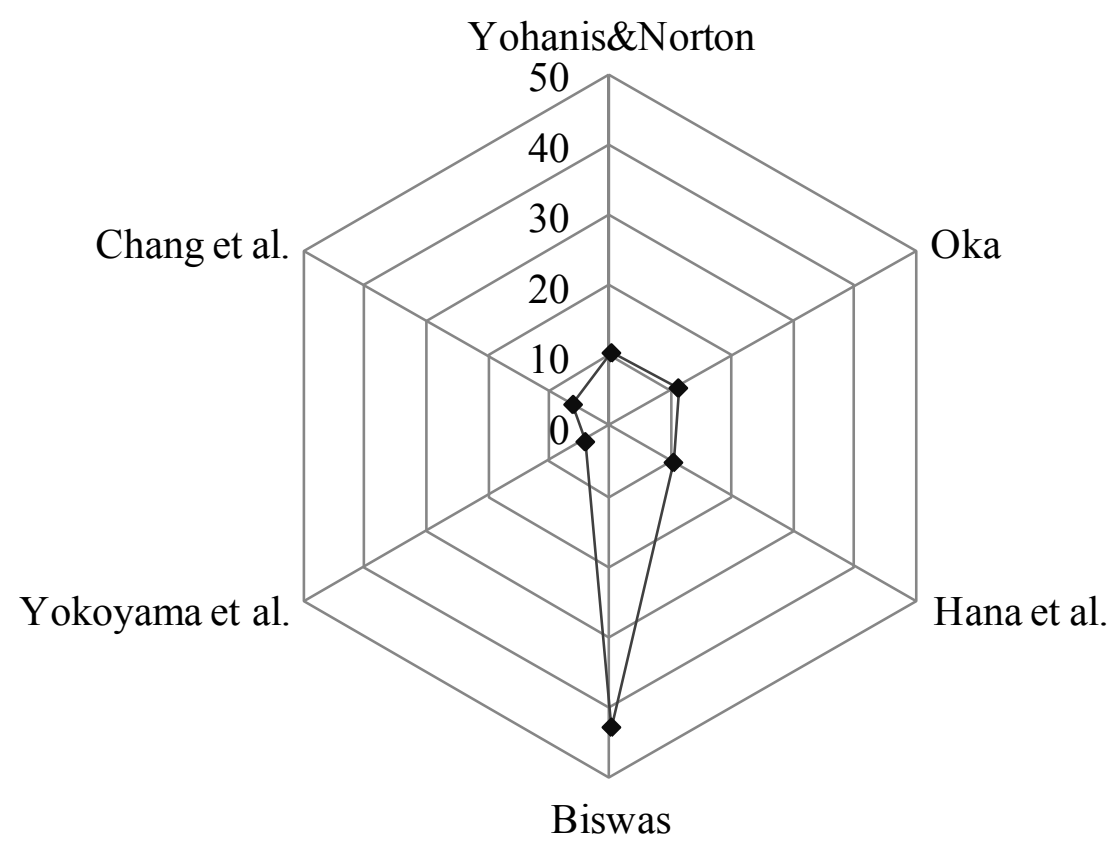

Figure 7. Results of embodied energy for commercial and public institutions building.

Therefore, although assessing results vary a lot from different studies, the embodied energy of commercial and public institutions building are more than residential buildings according to selected publications. And it is also demonstrated by Dixit et al. (2010).

Results discussion: According to analysis results in Figure 3, although Crawford (2011) demonstrated I/O-based hybrid is currently the preferred method due to advantage on completeness compared with other three methods, process-based hybrid and I/O-based hybrid are equal in number in selected publications. In this study found I/O-based hybrid only accounts for 9 percent of all study, which shows researchers still do not often utilized I/O-based hybrid in relevant study.

Results also show current researchers are more likely to adopt data sources from other research. Authors assume that it is because this type of data source is extensive and accessible. As analyzed above, some present research made use of database from different sources. This study found in total 43 percent of present study is using different database sources, which could impact the final results due to the different study boundaries, data quality and calculation method of these sources.

Yohanis and Norton (2002) expended the boundary of embodied energy from finish of building construction to deconstruction. Nevertheless, results of this paper review shows this kind of system boundary has not been utilized widely (14\% for refurbishment, renovation and maintenance, $25 \%$ for demolition).

This paper review also discovered that the embodied energy of residential building is less than commercial and public institute building in generally.

\section{CONCLUSION}

A vast amount of energy is consumed by construction industry. This paper review has employed reasonable paper searching, selection, analysis methods to investigate the inner information of current study weakness on construction embodied energy. Some useful details of weakness are found in this study, which are summarized as follows: 
(1) I/O-based hybrid method has not been widely utilized in present study, although it is regarded as the best method.

(2) In total 43 percent of present study adopt different database sources, which could influent the final results of embodied energy.

(3) The study boundary of most of present study still focus on embodied energy of material work, transportation and construction, only limited studies involve maintenance and demolition phases.

These findings about study weakness are meaningful for researchers in this field which help them deeply understand the present research states and study limitations. Also, it is helpful for them to overcome these weaknesses in further study. Meanwhile, three frequently mentioned weaknesses in this field are also verified in this paper review.

This paper review aims at grasp the general outlines of present study. Nevertheless, more publications need to be taken into account with the same method in this research so as to enhance the accuracy of final statistical data.

\section{ACKNOWLEDGMENTS}

This research was supported by the National Natural Science Foundation of China (No. 51378160).

\section{REFERENCES}

Abanda, F.H., Tah, J.H.M. and Cheung, F.K.T. (2013). "Mathematical modelling of embodied energy, greenhouse gases, waste, time-cost parameters of building projects: a review." Building \& Environment, 59(2013), 23-37.

Alwan, Z. and Jones, P. (2014). "The importance of embodied energy in carbon footprint assessment." Structural Survey, 32(1), 49-60.

Ardente, F., Beccali, M., Cellura, M. and Mistretta, M. (2008). "Building energy performance: a LCA case study of kenaf-fibres insulation board.” Energy \& Buildings, 40(1), 1-10.

Asif, M., Muneer, T. and Kelley, R. (2007). "Life cycle assessment: a case study of a dwelling home in Scotland." Building \& Environment, 42(3), 1391-1394.

Bansal, D., Singh, R. and Sawhney, R.L. (2014). "Effect of construction materials on embodied energy and cost of buildings: a case study of residential houses in India up to $60 \mathrm{~m}^{2}$ of plinth area." Energy and Buildings, 69(2014), 260-266.

Biswas, W.K. (2014). "Carbon footprint and embodied energy consumption assessment of building construction works in Western Australia." International Journal of Sustainable Built Environment, 3(2), 179-186.

Chang, Y., Ries, R. J. and Lei, S. (2012). "The embodied energy and emissions of a high-rise education building: a quantification using process-based hybrid life cycle inventory model." Energy and Buildings, 55(6), 790-798.

Chau, C., Soga, K., Nicholson, D., O’Riordan, N. and Inui, T. (2008). "Embodied energy as an environmental impact indicator for basement wall construction." Proceedings from GeoCongress, New Orleans, U.S., 867-874.

Chel, A. and Tiwari, G.N. (2009). "Thermal performance and embodied energy analysis of a passive house-Case study of vault roof mud-house in India." Applied Energy, 86(10), 19561969.

Crawford, R.H. (2009). "Life cycle energy and greenhouse emissions analysis of wind turbines and the effect of size on energy yield." Renewable \& Sustainable Energy Reviews, 13(9), 
2653-2660.

Crawford, R.H. (2011). "Validation of the use of input-output data for embodied energy analysis of the Australian construction industry." Journal of Construction Research, 6(1), 71-90.

Cui, L. (2005). Environmental impact assessment and case analysis, Standards Press of China, Beijing. (in Chinese).

Davies, P.J., Emmitt, S. and Firth, S.K. (2014). "Challenges for capturing and assessing initial embodied energy: a contractors' perspective." Construction Management and Economics, 32(3), 290-308.

Davies, P.J., Emmitt, S. and Firth, S.K. (2015). "Delivering improved initial embodied energy efficiency during construction." Sustainable Cities and Society, 14(1), 267-279.

Ding, G.K.C. (2004). The Development of A Multi-Criteria Approach for The Measurement of Sustainable Performance for Built Projects and Facilities. University of technology, Sydney, Australia, 52-55.

Dixit, M.K., Culp, C.H. and Fernández-Solís, J.L. (2013). "System boundary for embodied energy in buildings: a conceptual model for definition." Renewable \& Sustainable Energy Reviews, 21(5), 153-164.

Dixit, M.K., Culp, C.H. and Fernandez-Solis, J.L. (2015). "Embodied energy of construction materials: integrating human and capital energy into an IO-based hybrid model." Environmental science \& technology, 49(3), 1936-1945.

Dixit, M.K., Fernández-Solís, J.L., Lavy, S. and Culp, C.H. (2010). "Identification of parameters for embodied energy measurement: a literature review." Energy and Buildings, 42(8), 12381247.

Dixit, M.K., Fernández-Solís, J.L., Lavy, S. and Culp, C.H. (2012). "Need for an embodied energy measurement protocol for buildings: a review paper." Renewable \& Sustainable Energy Reviews, 16(6), 3730-3743.

Energy Information Administration (EIA). (2010). International energy outlook 2010, Washington, D.C.

Energy, U.S.D. (2012). "Buildings energy data book, chapter 1: Buildings sector." <http://buildingsdatabook.eren.doe.gov/ChapterIntro1.aspx>(Mar. 31, 2016).

Fieldson, R. and Rai, D. (2009). "An assessment of carbon emissions from retail fit-out in the United Kingdom.” Journal of Clinical Ethics, 8(2), 243-258.

Goggins, J., Keane, T. and Kelly, A. (2010). "The assessment of embodied energy in typical reinforced concrete building structures in Ireland." Energy and Buildings, 42(5), 735-744.

Gustavsson, L., Joelsson, A. and Sathre, R. (2010). "Life cycle primary energy use and carbon emission of an eight-storey wood-framed apartment building." Energy \& Buildings, 42(2), 230-242.

Hammond, G. and Jones, C. (2008). Inventory of carbon \& energy(ICE) version 1.6a, University of Bath Press, Bath.

Han, M.Y., Chen, G.Q., Shao, L., Li, J.S., Alsaedi, A., Ahmad, B., Guo, S., Jiang, M.M. and Ji, X. (2013). "Embodied energy consumption of building construction engineering: Case study in E-town, Beijing." Energy and Buildings, 64(5), 62-72.

Hashemi, A., Cruickshank, H. and Cheshmehzangi, A. (2015). "Environmental impacts and embodied energy of construction methods and materials in low-income tropical housing." Sustainability, 7(6), 7866-7883.

Hong, J., Shen, G.Q., Guo, S., Xue, F. and Zheng, W. (2016). "Energy use embodied in China's construction industry: A multi-regional input-output analysis." Renewable \& Sustainable 
Energy Reviews, 53(2016), 1303-1312.

Iddon, C.R. and Firth, S.K. (2013). "Embodied and operational energy for new-build housing: A case study of construction methods in the UK." Energy \& Buildings, 67(6), 479-488.

Jiang, Y. and Yang, X. (2006). "China building energy consumption situation and the problems exist in the energy conservation works." China Construction, (2), 12-17. (in Chinese).

Jiao, Y., Lloyd, C.R. and Wakes, S.J. (2012). "The relationship between total embodied energy and cost of commercial buildings." Energy and Buildings, 52(3), 20-27.

Junnila, S. and Horvath, A. (2003). "Life-cycle environmental effects of an office building." Journal of Infrastructure Systems, 9(4), 157-166.

Kishore, K.N. and Chouhan, J.S. (2014). "Embodied energy assessment and comparisons for a residential building using conventional and alternative materials in Indian context." Journal of The Institution of Engineers (India): Series A, 95(2), 117-127.

Kua, H.W. (2013). "The consequences of substituting sand with used copper slag in construction." Journal of Industrial Ecology, 17(6), 869-879.

Levin, H., Boerstra, A. and Ray, S. (1995). "Scoping US buildings inventory flows and environmental impacts in life cycle assessment." World Congress of the Society for Environmental Toxicology and Chemistry (SETAC), Vancouver, BC, Canada,

Li, X., Zhu, Y. and Zhang, Z. (2010). "An LCA-based environmental impact assessment model for construction processes." Building \& Environment, 45(3), 766-775.

Miller, D., Doh, J.H. and Mulvey, M. (2015). "Concrete slab comparison and embodied energy optimisation for alternate design and construction techniques." Construction and Building Materials, 80(2015), 329-338.

Monahan, J. and Powell, J. C. (2011). "An embodied carbon and energy analysis of modern methods of construction in housing: a case study using a lifecycle assessment framework." Energy and Buildings, 43(1), 179-188.

Noerwasito, V.T. (2011). "Evaluation of embodied energy and construction costs for the design of low-rise apartments for low-income residents in Surabaya, Indonesia." Journal of Civil Engineering and Architectur, 5(12), 1142-1146.

NIST Interagency/Internal Report (NISTIR). (2007). BEES 4.0: Building for environmental and economic sustainability technical manual and user guide, Washington, DC.

Omar, W.M.S.W., Doh, J.H. and Panuwatwanich, K. (2014). "Variations in embodied energy and carbon emission intensities of construction materials." Environmental Impact Assessment Review, 49(2014), 31-48.

Praseeda, K.I., Mani, M. and Reddy, B.V.V. (2014). “Assessing impact of material transition and thermal comfort models on embodied and operational energy in vernacular dwellings (India)." 4th International Conference on Advances in Energy Research 2013, Mumbai, India, 342-351.

Ramesh, T., Prakash, R. and Shukla, K.K. (2013). "Life cycle energy analysis of a multifamily residential house: A case study in Indian context." Open Journal of Energy Efficiency, 2(1), 34-41.

Rauf, A. and Crawford, R.H. (2015). "Building service life and its effect on the life cycle embodied energy of buildings." Energy, 79(2015), 140-148.

Reddy, B.V.V. and Jagadish, K.S. (2003). "Embodied energy of common and alternative building materials and technologies." Energy \& Buildings, 35(2), 129-137.

Reddy, B.V.V. and Kumar, P.P. (2010). "Embodied energy in cement stabilised rammed earth walls." Energy and Buildings, 42(3), 380-385. 
Reddy, B.V.V., Leuzinger, G. and Sreeram, V.S. (2014). "Low embodied energy cement stabilised rammed earth building-a case study." Energy \& Buildings, 68(2014), 541-546.

Rule, B.M., Worth, Z.J. and Boyle, C.A. (2009). "Comparison of life cycle carbon dioxide emissions and embodied energy in four renewable electricity generation technologies in New Zealand." Environmental Science \& Technology, 43(16), 1119-1126.

Salcido, J.C., Raheem, A.A. and Ravi, S. (2016). "Comparison of embodied energy and environmental impact of alternative materials used in reticulated dome construction." Building and Environment, 96(2016), 22-34.

Shukla, A., Tiwari, G.N. and Sodha, M.S. (2009). "Embodied energy analysis of adobe house." Renewable Energy, 34(3), 755-761.

Spence, R. and Mulligan, H. (1995). "Sustainable development and the construction industry." Habitat International, 19(3), 279-292.

Treloar, G.J. (1998). A Comprehensive Embodied Energy Analysis Framework. Deakin University, Victoria, Australia, 31-43.

Wang, E. and Shen, Z. (2014). "Improving uncertainty estimate of embodied-energy of construction materials using analytical hierarchical process in weighted DQI method." Construction Research Congress 2012, West Lafayette, U.S., 1840-1849.

Wen, T.J., Sionga, H.C. and Noor, Z.Z. (2015). "Assessment of embodied energy and global warming potential ofbuilding construction using life cycle analysis approach: Case studiesof residential buildings in Iskandar Malaysia.” Energy \& Buildings, 93(2015), 295-302.

Yeo, D. and Gabbai, R.D. (2011). "Sustainable design of reinforced concrete structures through embodied energy optimization." Energy and Buildings, 43(8), 2028-2033.

Yohanis, Y.G. and Norton, B. (2002). "Life-cycle operational and embodied energy for a generic single-storey office building in the UK." Energy, 27(1), 77-92.

Yokoyama, K., Yamamoto, M., Yokoo, N., Oka, T. and Sawach, T. (2015). "Study on Impact of Embodied Energy and C02 Emissions for Prolongation of Study in Japan." Journal of Civil Engineering and Architectur, 8(3), 274-282. 